\title{
PERFIL PSICOMOTOR DE CRIANÇAS EM SITUAÇÃO DE RISCO SOCIAL E COM DIFICULDADES NA ALFABETIZAÇÃO
}

\author{
PSYCHOMOTOR PROFILE OF CHILDREN IN SITUATIONS OF SOCIAL RISK AND \\ DIFFICULTIES IN LITERACY
}

\section{PERFIL PSICOMOTOR DE LOS NIÑOS EN SITUACIONES DE RIESGO SOCIAL Y CON DIFICULTADES EN LA ALFABETIZACIÓN}

Patrícia Pedron*

\begin{abstract}
Resumo: Os fatores biológicos somados à pobre estimulação ambiental e à falta de conhecimento e exploração das possibilidades corporais podem afetar a aprendizagem infantil. As dificuldades escolares podem estar relacionadas a deficiências de adaptação psicomotora que engloba problemas de desenvolvimento motor, de dominância lateral, de organização espacial, de estabilidade emotivoafetiva, que podem provocar alteração do comportamento infantil. O objetivo do estudo foi avaliar o grau de desenvolvimento psicomotor de crianças em situação de risco social de uma escola pública onde o Índice de Desenvolvimento da Educação Básica encontra-se abaixo da média nacional. Participaram dessa pesquisa quarenta crianças, de 06 a 07 anos, de ambos os sexos. As crianças foram avaliadas por meio da Escala de Desenvolvimento Motor para a avaliação do desenvolvimento psicomotor. Verificouse maior atraso no desenvolvimento motor no que se refere ao esquema corporal e à estruturação espacial, além do predomínio da lateralidade cruzada entre as crianças. Conclui-se que déficits em parâmetros psicomotores podem estar relacionados às dificuldades de aprendizagem e à baixa taxa de alfabetização apresentadas pelas crianças em situação de risco social, sendo que o acompanhamento do perfil psicomotor de crianças em idade escolar é uma atitude preventiva, pois contribui para a formulação de estratégias que envolvam a vivência e expressão corporal de forma a facilitar o processo de alfabetização. Além disso, destaca-se o importante papel de fatores ambientais (social e escolar) e da exploração corporal no desempenho das crianças, os quais são primordiais para o desenvolvimento de habilidades psicomotoras e aprendizagem adequada.
\end{abstract}

Palavras-chave: Desenvolvimento infantil. Avaliação. Movimento.

Abstract: Biological factors added to poor environmental stimulation and lack of knowledge and exploration of bodily possibilities can affect children's learning. The learning difficulties may be related to psychomotor adaptation deficiencies, which includes motor development problems, lateral dominance, spatial organization of emotional-affective stability that can cause change in child behavior. The study aimed to evaluate the degree of psychomotor development of children in situations of social risk in a public school where the Basic Education Development Index is below the national average. A total of forty children aged between 06 and 07 years old of both sexes participated in this research. The

\footnotetext{
* Fisioterapeuta pela Pontifícia Universidade Católica do Rio Grande do Sul Universidade Federal do Rio Grande do Sul. Estudante no Programa de Pós-Graduação (especialização) em Psicomotricidade Escolar pela Pontifícia Universidade Católica do Rio Grande do Sul. Mestranda no Programa de Pós-Graduação em Ciências da Reabilitação com ênfase em neurociências da Universidade de Ciências da Saúde de Porto Alegre. E-mail: patriciapedron16@yahoo.com.br
} 
children were evaluated by Motor Development Scale for the assessment of psychomotor development. There was greater delayed motor development in relation to the body structure and spatial structure, in addition to the predominance of cross laterally between the kids. We conclude that deficits in psychomotor parameters can be related to learning disabilities and low literacy rate given by children in social risk, and the monitoring of the psychomotor profile of children of school age is a preventive attitude, it contributes for the formulation of strategies that involve the experience and body language in order to facilitate the literacy process. In addition, there is the important role of environmental factors (social and school) and body exploration in children's performance, the latter being essential for the development of psychomotor skills and appropriate learning.

Keywords: Child development. Evaluation. Movement.

Resumen: Los factores biológicos sumados a la mala estimulación ambiental y a la falta de conocimiento y explotación de las posibilidades corporales pueden afectar el aprendizaje de los niños. Las dificultades de aprendizaje pueden estar relacionadas con deficiencias psicomotoras de adaptación, que incluyen problemas de desarrollo motor, dominancia lateral, organización espacial, la estabilidad emotivoafectiva, lo que puede causar cambios en el comportamiento del niño. El objetivo de este estudio fue evaluar el grado de desarrollo psicomotor de niños en situación de riesgo social en una escuela pública donde el Î́ndice de Desarrollo de la Educación Básica está abajo de la media nacional. Participaron de esa investigación cuarenta niños, de 06 a 07 años, de ambos sexos. Los niños fueron evaluados por medio de la Escala de Desarrollo motor para la evaluación del desarrollo psicomotor. Se verificó mayor retraso en el desarrollo motor en relación al esquema corporal y a la estructuración espacial, además de la predominancia de la lateralidad cruzada entre los niños. Se concluye que los déficit en los parámetros psicomotores pueden estar relacionados a las dificultades de aprendizaje y la baja tasa de alfabetización presentada por los niños en situación de riesgo social, siendo que, el acompañamiento del perfil psicomotor de los niños en edad escolar es una actitud preventiva, pues contribuye para la formulación de estrategias que involucren la vivencia y expresión corporal de forma que facilite el proceso de alfabetización. Además, se destaca el importante papel de los factores ambientales (sociales y escolares) y de la exploración corporal en el rendimiento de los niños, siendo éstos esenciales para el desarrollo de habilidades psicomotoras y aprendizaje apropiado.

Palabras-clave: Desarrollo del niño. Evaluación. Movimiento.

\section{Introdução}

A temática da alfabetização encontra-se em pauta no atual contexto das crianças brasileiras e remete a uma triste realidade, pois, apesar dos avanços, $11,5 \%$ das crianças de oito e nove anos são analfabetas, conforme divulgado pelo Instituto Brasileiro de Geografia e Estatística (IBGE) em 2011.

Atualmente, a qualidade da educação brasileira é avaliada pelo Índice de Desenvolvimento da Educação Básica (Ideb), criado pelo Instituto Nacional de Estudos e Pesquisas (Inep) em 2007 e que consiste em um indicador que reúne dois conceitos igualmente importantes para a qualidade da educação: a taxa de rendimento escolar (aprovação) e as médias de desempenho na Provinha Brasil. Analisando-se os resultados do Ideb de 2013, a realidade que se apresenta em muitas regiões do país, incluindo o RS, é a existência de crianças com baixo índice de alfabetização, muitas delas oriundas de famílias que vivem em situações de grande pobreza e risco social. Segundo o Estatuto da Criança e do Adolescente (1990), por situação de risco entende-se a condição de crianças que, em função das suas circunstâncias de vida, estão 
expostas à violência, ao uso de drogas e a um conjunto de experiências relacionadas às privações de ordem afetiva, cultural e socioeconômica que desfavorecem o pleno desenvolvimento biopsicossocial.

Numa sociedade onde o sucesso pessoal e socioprofissional depende cada vez mais das competências que se adquirem na escola, ter insucesso escolar significa estar em "risco" de se tornar um cidadão dependente, sem qualificações e vítima do contexto; dessa forma, o fenômeno do insucesso escolar apresenta-se como um problema individual, mas também social. (VILLAS, 1998).

O aprendizado ocorre ao longo do desenvolvimento infantil, quando as experiências sensório-motoras advindas da exploração do ambiente são enriquecidas com a variabilidade e complexidade do próprio ambiente. (LIMA; BELTRÃO; LOPES, 2001). Paralelamente aos fatores de risco biológicos, as desvantagens ambientais podem influenciar negativamente o desenvolvimento das crianças. (ANDRACA et al., 1998). Há evidências de que um ambiente positivo, rico em estímulos, age como facilitador do desenvolvimento normal, pois possibilita a exploração e interação com o meio. Entretanto, o ambiente com pobre estimulação sensorial, motora e afetiva pode atrasar o ritmo de desenvolvimento e restringir as possibilidades de aprendizagem do indivíduo. Considera-se que a parcela mais desfavorecida da população acumula os fatores (ambientais e biológicos) que determinam uma maior chance de atraso no desenvolvimento das crianças. (AYLWARD, 1997).

Os fatores biológicos somados à pobre estimulação ambiental e à falta de conhecimento e exploração das possibilidades corporais podem afetar a aprendizagem infantil visto que a criança tem seu corpo como referência na interação com o mundo em que está inserida. Um corpo não organizado, que não obedece a seus próprios comandos, pode interferir no desenvolvimento intelectual, social e mesmo afetivo-emocional, dificultando a aprendizagem na escola.(OLIVEIRA, 1992).

Segundo Fonseca (1998), as dificuldades escolares podem estar relacionadas com deficiências de adaptação psicomotora, que engloba problemas de desenvolvimento motor, de dominância lateral, de organização espacial, de estabilidade emotivo-afetiva, que podem provocar alteração do comportamento infantil.

De acordo com Le Boulch (1992), a educação psicomotora ou psicomotricidade refere-se a uma formação de bases indispensáveis a toda criança, pois responde a uma dupla finalidade: assegurar o desenvolvimento funcional e motor, tendo em conta as possibilidades da criança, e ajudar a sua afetividade a expandir-se e equilibrar-se através do intercâmbio com o ambiente humano.

Dentro do ambiente escolar, Defontaine (1981) diz que a psicomotricidade ajuda no processo de leitura e escrita, pois antes que a criança aprenda a ler, isto é, antes de sua entrada nas séries primárias, o trabalho psicomotor terá como objetivo proporcionar-lhe uma motricidade espontânea, coordenada e rítmica, que será o melhor aval para evitar problemas na disgrafia, pois a escrita é, antes de qualquer coisa, um aprendizado motor.

De acordo com Vilar (2010), a psicomotricidade influencia a aprendizagem ocorrendo primeiramente pela experimentação motora, principalmente pela motricidade intencional, visto que a criança desenvolve noções espaciais e temporais, movimentos coordenados e planificados, a capacidade para resolver problemas e procura estratégias que são requisitos básicos para as aprendizagens escolares.

A fim de que se adotem práticas educativas capazes de auxiliar na promoção da 
alfabetização de crianças em situação de risco social, é emergente e necessário o entendimento dos fatores que podem estar interferindo negativamente neste processo. Considerando que alguns destes fatores podem estar relacionados ao desenvolvimento psicomotor destas crianças, muitas vezes privadas da estimulação ambiental necessária ao desenvolvimento psicológico e sensório-motor adequado, este estudo teve como objetivo avaliar o grau de desenvolvimento psicomotor de crianças em situação de risco social de uma escola pública na periferia de Porto Alegre (RS), onde o Ideb encontra-se abaixo da média nacional.

\section{Material e métodos}

Este estudo caracterizou-se como uma pesquisa descritiva, de corte transversal, e foi realizada após a aprovação do Comitê de Ética em Pesquisa da Universidade Federal do Rio Grande do Sul (UFRGS). A população foi escolhida de maneira intencional e, nesse sentido, foram selecionados alunos da escola com menor Ideb dentre as escolas de Porto Alegre, no ano de 2013 (ideb.inep.gov.br), ou seja, com menor taxa de alfabetização. A amostra constituiu-se de crianças que frequentavam o primeiro ano do Ensino Fundamental da Escola Estadual Alvarenga Peixoto, POA/RS. Foram incluídas no estudo 40 crianças. Os critérios de inclusão foram: (1) estar regularmente matriculado no primeiro ano do Ensino Fundamental da Escola Alvarenga Peixoto; (2) ter idade entre 06 e 07 anos; (3) assinar o Termo de Consentimento Livre e Informado. Os critérios de exclusão foram: presença de deficiência física, déficits sensoriais, transtornos comportamentais e/ou deficiência mental que impeça a realização dos testes da Escala de Desenvolvimento Motor (EDM).

A pesquisa foi realizada no primeiro semestre do ano de 2013. Após a assinatura do
Termo de Consentimento Livre e Informado pelos pais ou responsáveis, as crianças foram avaliadas em uma sala da própria escola, com boa ventilação e iluminação e que continha os materiais adequados para a aplicação da EDM. As tarefas foram previamente explicadas para que as crianças se sentissem tranquilas e seguras, conseguindo, assim, realizá-las dentro dos parâmetros requeridos.

$\mathrm{O}$ instrumento utilizado para avaliar o desenvolvimento psicomotor dos escolares foi o Protocolo de testes da Escala de Desenvolvimento Motor de Rosa Neto(2002), que avalia as seguintes áreas do desenvolvimento: motricidade fina ou óculo manual (IM1), motricidade global ou coordenação (IM2), equilíbrio ou postura estática (IM3), esquema corporal ou imitação de postura e rapidez (IM4), organização espacial ou percepção do espaço (IM5), organização temporal ou linguagem (IM6) e lateralidade (mãos, pés e olhos). Este instrumento determina a idade motora geral (obtida através dos pontos alcançados nos testes) e o quociente motor (obtido através da divisão entre a idade motora e idade cronológica multiplicada por 100). Com exceção dos testes de lateralidade, as outras baterias consistem em 10 tarefas motoras cada, distribuídas entre 2 e 11 anos, organizadas progressivamente em grau de complexidade, sendo atribuído para cada tarefa, em caso de êxito, um valor correspondente a idade motora (IM), expressa em meses. Em cada bateria, o teste é interrompido quando a criança não concluir a tarefa com êxito, conforme protocolo. Ao final da aplicação, dependendo do desempenho individual em cada bateria, é atribuída à criança uma determinada IM, em cada uma das áreas referidas anteriormente (IM1, IM2, IM3, IM4, IM5, IM6), sendo posteriormente calculada a idade motora geral (IMG) e o quociente motor geral (QMG) da criança. Esses valores são quantificados e categorizados, permitindo classificar 
as habilidades analisadas em padrões: muito superior (130 pontos ou mais), superior (120129 pontos), normal alto (110-119 pontos), normal médio (90-109 pontos), normal baixo (80-89 pontos), inferior (70-79 pontos) e muito inferior (69 ou menos pontos).

A Escala de Desenvolvimento Motor para se obter a Idade Motora Geral (IMG) foi aplicada por dois avaliadores previamente treinados. A aplicação teve duração de aproximadamente 30 minutos para cada aluno, e o período de coleta de dados estendeu-se por 2 meses. As crianças foram avaliadas individualmente, conforme agendamento prévio com a equipe pedagógica da escola e avaliadores.

Os dados sociodemográficos coletados incluíram informações referentes à quantidade de alunos que possuem o benefício da bolsa família, com quem as crianças moram, quantidade de pessoas que residem no mesmo lar dos avaliados, a renda mensal familiar, bem como a idade, a profissão, a escolaridade e o estado civil dos pais ou responsáveis. A coleta foi realizada por meio de entrevista, utilizando-se um questionário elaborado pela pesquisadora.

Os dados foram organizados e tabulados utilizando-se o programa SPSS Statistical Package for Social Sciences v. 11.5. Para o tratamento descritivo dos dados foi utilizada a análise das médias, desvio padrão, valor mínimo e valor máximo, percentual e frequência.

\section{Resultados}

Foram avaliados 40 alunos do primeiro ano do Ensino Fundamental da escola Alvarenga Peixoto, sendo 57,5\% do sexo feminino e $42,5 \%$ do sexo masculino, com idade média de 6,81 anos (Tabelas 1 e 2).
Tabela 1: Caracterização da amostra quanto ao gênero.

\begin{tabular}{c|c|c}
\hline Classificação & Frequência & $\mathbf{\%}$ \\
\hline Feminino & 23 & 57,5 \\
\hline Masculino & 17 & 42,5 \\
\hline Total & 40 & \\
\hline
\end{tabular}

Fonte: a autora.

Tabela 2: Distribuição das idades.

\begin{tabular}{c|c|c}
\hline Idade em anos & Frequência & $\mathbf{\%}$ \\
\hline 6 & 15 & 37,5 \\
\hline 7 & 25 & 62,5 \\
\hline Total & 40 & 100 \\
\hline
\end{tabular}

Fonte: a autora.

As principais características sociodemográficas estão expostas na Tabela 3.

Tabela 3: Dados Sociodemográficos.

\begin{tabular}{|c|c|}
\hline $\begin{array}{l}\text { Benefício da } \\
\text { bolsa família }\end{array}$ & $\begin{array}{l}\text { 76,1 \% com bolsa } \\
\text { 23,9\% sem bolsa }\end{array}$ \\
\hline $\begin{array}{l}\text { Profissão do } \\
\text { Entrevistado } \\
\text { (pais ou } \\
\text { responsável) }\end{array}$ & $\begin{array}{l}\text { 42,8\% do lar } \\
\text { 21,1\% catador de lixo } \\
\text { 15\% pedreiro } \\
\text { 9,5\% auxiliar de cozinha } \\
\text { 9,5\% caseiro } \\
\text { 2,1\% autônoma } \\
\end{array}$ \\
\hline $\begin{array}{l}\text { Escolaridade } \\
\text { do Entrevistado } \\
\text { (pais ou } \\
\text { responsável) }\end{array}$ & $\begin{array}{l}1^{\circ} \text { Grau Incompleto: 52,5 \% } \\
1^{\circ} \text { Grau Completo: } 24 \% \\
2^{\circ} \text { Grau Incompleto: } 14 \% \\
\text { Analfabeto: } 9,5 \%\end{array}$ \\
\hline $\begin{array}{l}\text { Renda Mensal } \\
\text { Familiar } \\
\text { (com valor da } \\
\text { bolsa família } \\
\text { incluso). }\end{array}$ & $\begin{array}{l}400,00 \text { a } 800,00: 43 \% \\
800,00 \text { a } 1000,00: 9,5 \% \\
1000,00 \text { a } 1.200,000: 9,5 \% \\
1.200,00 \text { a } 1.500,00: 19 \% \\
1.500,00 \text { a } 2.000,00: 19 \%\end{array}$ \\
\hline $\begin{array}{l}\text { Quantidade de } \\
\text { pessoas que } \\
\text { residem na } \\
\text { mesma casa }\end{array}$ & $\begin{array}{l}\text { De } 2 \text { a } 3: 23,8 \% \\
\text { De } 4 \text { a } 5: 47,8 \% \\
\text { De } 6 \text { a } 7: 19 \% \\
\text { De } 8 \text { a } 9: 4,7 \% \\
\text { De } 9 \text { a } 11: 4,7 \%\end{array}$ \\
\hline
\end{tabular}

Fonte: a autora. 
De acordo com os resultados obtidos através da aplicação da EDM observou-se que a maioria dos alunos apresentou desenvolvimento motor normal (90\%) (Tabela 4), verificado através do cálculo do quociente motor geral $(103,16 \pm 12,08)$ (Tabela 5). Quando as variáveis que compõem a EDM foram analisadas separadamente, observou-se que os alunos apresentaram desempenho motor acima do esperado em relação à motricidade fina, motricidade global e equilíbrio (Tabela 5), porém, em relação ao esquema corporal (6,05 $\pm 1,33)$ e organização espacial $(5,57 \pm 0,98)$, as crianças apresentaram desempenho motor abaixo do esperado para a idade (Tabela 5).
Tabela 4: Classificação geral dos resultados da EDM.

\begin{tabular}{c|c|c}
\hline Classificação & Frequência & $\mathbf{\%}$ \\
\hline Muito superior & 1 & 2,5 \\
\hline Superior & 3 & 7,5 \\
\hline Normal alto & 7 & 17,5 \\
\hline Normal médio & 25 & $\mathbf{6 2 , 5}$ \\
\hline Normal baixo & 4 & 10 \\
\hline Inferior & 0 & 0 \\
\hline Muito inferior & 0 & 0 \\
\hline Total & 40 & 100 \\
\hline
\end{tabular}

Fonte: a autora.

Tabela 5: Perfil motor geral do grupo.

\begin{tabular}{c|c|c|c|c}
\hline Variável & Média & Desvio Padrão & Valor Mínimo & Valor Máximo \\
\hline Idade cronológica & $\begin{array}{c}81,83 \text { meses } \\
(6,81 \text { anos })\end{array}$ & 4,41 & 76 & 92 \\
\hline Idade motora geral & $\begin{array}{c}83,875 \text { meses } \\
(6,9 \text { anos })\end{array}$ & 10,57 & 61 & 110 \\
\hline Motricidade fina & 7,83 & 1,20 & 5 & 10,5 \\
\hline Motricidade global & 7,8 & 1,54 & 5 & 11 \\
\hline Equilíbrio & 7,525 & 1,74 & 4 & 11 \\
\hline Esquema corporal & $\mathbf{6 , 0 5 *}$ & 1,33 & 4 & 11 \\
\hline Organização espacial & $\mathbf{5 , 5 7 *}$ & 0,98 & 4 & 130,9 \\
\hline Organização temporal & 7,15 & 1,87 & 40,2 & 8 \\
\hline Quociente motor geral & 103,16 & 12,08 & & \\
\hline
\end{tabular}

* Valores abaixo do previsto para a idade cronológica.

Fonte: a autora. 
Das 40 crianças avaliadas, 52,5\% apresentaram a idade motora, em relação ao esquema corporal, abaixo do esperado para a sua idade, e 70\% das crianças obtiveram desempenho abaixo do esperado no que diz respeito à organização espacial. Além disso, 25\% e 20\% das crianças apresentaram desempenho motor relacionado à organização temporal e ao equilíbrio, respectivamente, abaixo do esperado para a sua idade.

Os resultados obtidos indicam que $52,5 \%$ das crianças avaliadas apresentaram lateralidade cruzada ou indefinida, enquanto $47,5 \%$ apresentaram lateralidade definida (Tabela 6). Das crianças com desempenho geral na EDM abaixo do esperado para a sua idade, 71,42\% apresentaram lateralidade cruzada ou indefinida, ou seja, não apresentam dominância em relação a um dos lados do corpo quanto à realização de atividades psicomotoras.
Tabela 6. Classificação geral da lateralidade.

\begin{tabular}{c|c|c}
\hline Classificação & Frequência & $\mathbf{\%}$ \\
\hline Destro & 17 & 42,5 \\
\hline Sinistro & 2 & 5 \\
\hline Cruzada & 20 & 50 \\
\hline Indefinida & 1 & 2,5 \\
\hline Total & 40 & 100 \\
\hline
\end{tabular}

Fonte: a autora.

Em relação ao gênero, os resultados indicam que as meninas apresentaram desempenho motor abaixo do esperado para a idade nas variáveis relacionadas ao esquema corporal e organização espacial (Tabela 7). Os meninos apresentaram, adicionalmente, desempenho abaixo do esperado no que se refere à organização temporal (Tabela 8).

Tabela 7: Perfil motor relacionado ao gênero (sexo feminino).

\begin{tabular}{c|c|c}
\hline Variável & Média & Desvio Padrão \\
\hline Idade cronológica & $\begin{array}{c}81,37 \text { meses } \\
(6,7 \text { anos })\end{array}$ & 4,33 \\
\hline Idade motora geral & $\begin{array}{c}87,13 \text { meses } \\
(7,2 \text { anos })\end{array}$ & 10,80 \\
\hline Motricidade fina & 7,89 & 1,16 \\
\hline Motricidade global & 7,78 & 1,55 \\
\hline Equilíbrio & 7,91 & 1,76 \\
\hline Esquema corporal & $\mathbf{6 , 5 2} * 47$ \\
\hline Organização espacial & $\mathbf{5 , 6 9 *}$ & 1,18 \\
\hline Organização temporal & 7,76 & 1,98 \\
\hline Quociente motor geral & 106,87 & 12,04 \\
\hline
\end{tabular}

* Desempenho abaixo do esperado para a idade cronológica.

Fonte: a autora. 
Tabela 8: Perfil motor relacionado ao gênero (sexo masculino).

\begin{tabular}{c|c|c}
\hline Variável & Média & Desvio Padrão \\
\hline Idade cronológica & $\begin{array}{c}81,82 \text { meses } \\
(6,81 \text { anos })\end{array}$ & 4,01 \\
\hline Idade motora geral & $\begin{array}{c}79,47 \text { meses } \\
(6,62 \text { anos })\end{array}$ & 8,71 \\
\hline Motricidade fina & 7,74 & 1,29 \\
\hline Motricidade global & 7,82 & 1,62 \\
\hline Equilíbrio & 7 & 0,79 \\
\hline Esquema corporal & $\mathbf{5 , 4 1 *}$ & 0,61 \\
\hline Organização espacial & $\mathbf{z 5 , 4 1 *}$ & 1,38 \\
\hline Organização temporal & $\mathbf{6 , 3 2 *}$ & 10,47 \\
\hline Quociente motor geral & 98,12 &
\end{tabular}

* Desempenho abaixo do esperado para a idade cronológica.

Fonte: a autora.

\section{Discussão}

Este estudo teve como objetivo avaliar o grau de desenvolvimento psicomotor de crianças em situação de risco social de uma escola pública na periferia de Porto Alegre (RS), utilizando como instrumento de avaliação a Escala de Desenvolvimento Motor (EDM) de Rosa Neto (2002). Os resultados obtidos indicam que os alunos avaliados apresentaram, em sua maioria, desenvolvimento motor normal. No momento em as variáveis que compõem a EDM foram analisadas separadamente, observou-se que os alunos apresentaram desempenho motor acima do esperado em relação à motricidade fina, motricidade global e equilíbrio, porém, em relação ao esquema corporal e organização espacial as crianças apresentaram desempenho motor abaixo do esperado para a idade. Os resultados também indicam que $52,5 \%$ das crianças avaliadas apresentaram lateralidade cruzada ou indefinida

De acordo com Oliveira (2001), a motricidade global é o resultado de ações de um grupo de músculos trabalhando em conjunto.
Ela depende do controle motor e do equilíbrio postural, estando este subordinado a várias sensações e ao controle do cerebelo. A criança, através de suas experiências com o meio, busca seu eixo corporal, centro gravitacional, levando-a ao melhor ponto de equilíbrio. A motricidade global é constituída através das brincadeiras, gestos, atitudes, deslocamentos que a criança realiza, bem como a relação desses fatores com o meio em que está vivendo. Em relação ao equilíbrio, Fonseca (1998) refere que a equilibração é um dos fatores básicos da organização psicomotora, pois envolve muitos ajustamentos na postura, que é pré-requisito para qualquer resposta motora. Le Boulch (1992) ressalta que a conscientização das relações de equilibração representa uma condição fundamental ao enriquecimento da imagem corporal e às possibilidades de acesso a um bom ajustamento postural com representação mental para o aprendizado escolar. Rosa Neto (2002) salienta que o equilíbrio trata-se do principal segmento da motricidade humana e dificuldades neste aspecto geram movimentos lentos, com grande consumo de energia, sendo que tal gasto energético poderia ser 
canalizado para outros trabalhos neuromusculares. O bom desempenho, observado neste estudo, para o componente equilíbrio está em conformidade com os resultados encontrados por Gallahue e Ozmun (2001), de que por volta dos sete anos de idade as crianças já são capazes de manter o equilíbrio mesmo com os olhos fechados, melhorando a capacidade de equilibrar-se com o aumento da idade. Estudos como o de Crippa e Liamara (2003) ao verificar o perfil motor de escolares com idade entre 5 e 6 anos, através da Escala de Desenvolvimento Motor, também encontraram bom desempenho nas variáveis equilíbrio, coordenação motora geral e fina em escolares, corroborando nossos achados. Outro estudo que obteve resultados semelhantes é o de Fonseca, Beltrame e Tkac (2008), que avaliou 34 escolares, com idade entre 6 e 9 anos que obtiveram um bom desempenho nas habilidades anteriormente citadas.

Acredita-se que o bom desempenho nos parâmetros psicomotores, motricidade global e equilíbrio, apresentado pelas crianças avaliadas neste estudo, pode estar relacionado ao tipo de atividade que elas praticam no período extraescolar, possivelmente dedicado a brincadeiras que exploram movimentos globais e desafiam o equilíbrio, como jogos com bolas, "pega-pega”, “esconde-esconde”, subir em árvores, dentre outras. Uma vez que essas crianças não têm acesso a computadores e outros brinquedos, além do próprio corpo, em função da situação de pobreza em que vivem, possivelmente sejam impelidas a divertir-se com atividades que proporcionam experiências motoras que podem estimular a aquisição de habilidades de equilibração e de motricidade mais globais.

Em relação à motricidade fina, sabe-se que um dos enfoques do trabalho pedagógico com crianças em idade de alfabetização é o desenvolvimento desta habilidade através de atividades como recortar, pintar, colar, desenhar, escrever, etc. Rosa Neto (2002) refere que estas atividades escolares, nas quais os alunos necessitam coordenar os componentes objeto-olho-mão, são imprescindíveis no processo de aquisição da motricidade fina. As crianças avaliadas neste estudo foram estimuladas a executar atividades deste tipo em sala de aula, o que pode ter contribuído para o bom desempenho que obtiveram na avaliação deste parâmetro psicomotor.

Ao analisarmos as variáveis que compõem a EDM, observa-se que, em relação ao esquema corporal, 52,5\% das crianças apresentaram desempenho abaixo do esperado para sua idade cronológica e na classificação da EDM se encontram com um perfil motor considerado inferior para a sua idade nessa habilidade. Os estudos como o de Rosa Neto e Poeta (2004) também encontraram os mesmos resultados no que se refere ao baixo desempenho no esquema corporal. Adotando a Escala de Desenvolvimento Motor (EDM), avaliaram 51 crianças entre 4 e 12 anos com dificuldade de aprendizagem encaminhadas ao programa de psicomotricidade da UDESC, e o grupo foi classificado como inferior ao esperado para o esquema corporal. Rosa Neto e Poeta (2005) encontrou a mesma classificação no estudo com 52 alunos que tinham diagnóstico de Transtorno de Déficit de Atenção e Hiperatividade (TDAH) e eram de ambos os gêneros, com idade entre 6 e 10 anos, matriculados nos anos iniciais do Ensino Fundamental, sendo que, em ambos os estudos, grande parte dos estudantes era proveniente de famílias com alterações psicossociais, sugerindo correlação entre esses fatores. A pesquisa de Costa (2000) vai ao encontro destes achados, em que foram avaliadas 105 crianças na faixa etária entre 5 e 14 anos, com queixa de dificuldade de aprendizagem; como resultado obteve-se uma classificação do esquema corporal inferior ao esperado. Conforme Oliveira (1992), 
as dificuldades no esquema corporal podem levar as crianças a apresentarem problemas na coordenação dos movimentos e lentidão na realização de gestos harmoniosos simples entre eles: abotoar uma roupa, jogar bola, andar de bicicleta, entre outras atividades, pela falta de domínio do corpo em ação. Segundo a autora, as perturbações no esquema corporal podem levar a uma impossibilidade de apropriação dos esquemas dinâmicos que correspondem ao hábito visuomotor e também intervém na leitura e escrita. Na escrita, a criança pode não dispor bem as palavras e não obedecer aos limites da folha, não conseguir trabalhar com vírgulas, pontos, nem armar corretamente contas e assim apresentar dificuldades na aprendizagem.

A análise psicomotora deste estudo indicou que $70 \%$ das crianças avaliadas possuem a idade motora, no que diz respeito à habilidade de estruturação espacial, classificada como inferior para sua idade cronológica. Esse resultado corrobora os achados de Rosa Neto e Poeta (2004) sobre o desenvolvimento motor de crianças com indicadores de dificuldades de aprendizagem. Os autores revelaram que um número significativo de educandos com dificuldades na aprendizagem escolar apresentou importante atraso no desenvolvimento motor no que se refere à organização espacial e esquema corporal. (ROSA NETO; POETA, 2005). Ferreira (2007) ao avaliar 52 escolares da rede pública de São Jose/SC, na faixa de 6 a 11 anos, com dificuldade de aprendizagem, encontrou maior déficit nas habilidades de organização espacial e de organização temporal. Le Boulch(1987) salienta que problemas de falta de estruturação espacial geram desinteresse pelas matérias escolares e falta de motivação para a aprendizagem da leitura e da escrita, sendo fundamental a percepção e a representação mental do espaço quando se lê e se escreve. A representação mental é retratada pela imagem do corpo orientando desempenho importante no ingresso ao universo projetivo e euclidiano, no qual se desenvolve o ato gráfico. No processo de organização espacial, é fundamental que o indivíduo tenha domínio dos movimentos e consciência de cada segmento corporal, para ser capaz de realizar um trabalho sensorial mais elaborado, bem como fazer a associação dos componentes corporais aos diversos objetos da vida cotidiana, além de possuir um conhecimento mais analítico do espaço e dos gestos, isto é, das diferentes posições que fazemos cada parte do corpo adotar. (MEUR; SATAES, 1989). As células que são envolvidas na organização espacial são as células place, e evidências indicam que o hipocampo é o responsável pela organização da memória espacial, apresentando uma rede neural bastante flexível para resolver novos problemas, mais especificamente, o giro denteado está envolvido nas novas detecções espaciais e visuais. (DIBA; BUZSÁKI, 2007).

Assim, na criança, a organização espacial se desenvolve perante o conhecimento que ela tem do seu corpo e do lugar que ocupa. A estruturação espacial é uma habilidade que está intimamente ligada à lateralidade, como se observa nos resultados deste estudo, em que 52,5\% das crianças apresentaram lateralidade cruzada ou indefinida, ou seja, não há dominância em relação a uma das partes do corpo (direita ou esquerda). O termo lateralidade se refere a "prevalências motoras de um lado do corpo”. Essa lateralização motora coincide com a predominância sensorial do mesmo lado e com as possibilidades simbólicas do hemisfério cerebral oposto. Dessa maneira, é possível aceitar a ideia de que a lateralização não se manifesta somente por meio de aferências sensoriais e sensitivas, e sim por meio da diferenciação funcional de ambas as metades do cérebro. A automatização da lateralização tanto é necessária quanto indispensável, e esse conhecimento deve ser 
automatizado o mais cedo possível. Alguns autores afirmam que a lateralidade está relacionada ao conhecimento corporal, o qual é de grande importância nas relações entre o eu e o mundo exterior, e é, segundo Wallon, um elemento indispensável na constituição da personalidade do ser humano. O conhecimento do corpo não depende unicamente do desenvolvimento cognitivo; depende, também, da percepção formada tanto de sensações visuais, táteis, sinestésicas quanto, em parte, da contribuição da linguagem. A lateralização, além de ser uma característica da espécie humana em si, põe em jogo a especialização hemisférica do cérebro e reflete a organização funcional do sistema nervoso central. A conscientização do corpo pressupõe a noção de esquerda e direita, sendo que a lateralidade com mais força, precisão, preferência, velocidade e coordenação participa no processo de maturação psicomotora da criança. A capacidade de a criança ascender à simbolização passa pela dominância cerebral, pois, caso contrário, resulta em distúrbios quer na linguagem falada, quer na linguagem escrita. Além disso, a lateralidade complementa uma função coordenada com a dominante: trata-se de uma direção assegurada por um dos membros ao realizarmos uma série de movimentos ou ao entrar em jogo um conjunto neuromuscular. (PACHER, 2015). Ao analisar-se a lateralidade das crianças com desempenho geral abaixo do esperado na EDM, o número das que não possuem uma definição do lado dominante aumenta, passando a ser de 71,42\%. Na pesquisa de Rosa Neto et al. (2010) foram encontrados resultados semelhantes aos nossos, ou seja, aproximadamente $1 / 3$ dos escolares entre 6 a 10 anos apresentaram a lateralidade cruzada, o que, segundo o autor, apoiava a baixa classificação que obtiveram na orientação espacial. Rodrigues (2000), em seu estudo com crianças de 2 a 6 anos de idade, matriculadas na Educação Infantil de duas escolas em Florianópolis/SC, afirma que a organização espacial é parte integrante da lateralidade e, por isso, um desempenho baixo na estruturação espacial pode estar relacionado à presença de lateralidade cruzada que foi encontrada em sua pesquisa. De acordo com Meur e Sataes (1989), a lateralidade é extremamente relevante para o desenvolvimento infantil por influir diretamente na ideia que a criança tem de si mesma, na formação de seu esquema corporal, estrutura espacial e na percepção da simetria do corpo. Para o autor, o desenvolvimento dessa habilidade contribui para determinar a estruturação espacial, pois, ao perceber o eixo de seu corpo, a criança percebe também seu meio ambiente em relação a esse eixo, os conceitos acima e abaixo e a discriminação de letras e palavras quando deparados com o papel. As dificuldades nesta habilidade podem levar a um desempenho empobrecido quando as crianças se deparam com a alfabetização, já que elas podem apresentar esquecimento ou confusão dos significados dos símbolos que as letras representam, problemas com a direção das letras, dificuldades em reversibilidade e transposição, falta de compreensão das relações espaciais e até falta de controle espacial do próprio corpo, esbarrando ou chocando-se com objetos constantemente. Observa-se, então, que todas as variáveis da EDM se inter-relacionam.

Quanto ao desempenho motor no que diz respeito à organização temporal, é possível verificar que $25 \%$ das crianças possuem a idade motora abaixo do esperado para sua idade. Quando analisamos esse desempenho motor relacionado ao gênero masculino e feminino, observa-se que o sexo masculino possui um déficit nesta habilidade. Outros estudos também encontraram alterações na organização temporal. Medina, Rosa e Marques (2006) analisou o desenvolvimento motor em 34 crianças com dificuldade de aprendizagem entre 8 e 10 anos de idade e verificou que 
a maior parte da amostra (53\%) apresentou idade motora inferior à sua idade cronológica, com maior atraso nos testes de organização temporal, seguido do esquema corporal e organização espacial. O estudo de Rosa Neto (2002) avaliou crianças de 8 a 10 anos de idade praticantes de natação, utilizando o mesmo protocolo adotado no presente estudo, obtendo como resultado do teste de organização temporal um desempenho baixo em relação à idade motora das crianças. De acordo com os autores, na infância o movimento se faz mais interessante, no sentido de ser explorado a fim de que as crianças possam ter um processo de crescimento ativo. A importância da investigação sobre o desenvolvimento da organização espaço-temporal em crianças se dá pelo fato de que a capacidade de discriminação auditiva e rítmica, que diz respeito à localização do som no espaço e às mudanças dos dados temporais, é fundamental para o processo de aprendizagem acadêmica. A noção de organização temporal é estabelecida pela compreensão da sucessão e periodicidade, a partir das mudanças que ocorrem ao longo do tempo. De acordo com Neira(2003), as crianças só lidam com o tempo no presente, porém, à medida que aprendem a ordenar os acontecimentos e a tomar consciência dos intervalos temporais entre eles desenvolvem uma compreensão intuitiva de tempo, baseada na sucessão dos eventos e na duração dos intervalos. Percebemos o transcurso do tempo a partir das mudanças que se produzem durante um período estabelecido e da sua sucessão, que transforma progressivamente o futuro em presente e, depois, em passado. (ROSA NETO, 2002). Como visto anteriormente, as crianças avaliadas no presente estudo também possuem déficits nas tarefas de noção corporal e espacial, e isto pode resultar em atraso no desenvolvimento da organização temporal das crianças, visto que a aquisição de conceitos referentes ao espaço e ao tempo não poderá ser compreendida sem se fazer referência à evolução do esquema corporal.

O percentual de crianças abaixo da média no desempenho motor em relação ao esquema corporal, à estruturação espacial e à organização temporal pode ser explicado, pois determinados déficits nas funções psicomotoras podem ter etiologia relacionada a fatores sociais e do meio ambiente em que a criança está inserida. A aprendizagem motora depende da associação das características herdadas com experiências vividas, sendo o meio onde vive uma rica fonte de mudanças que influencia o desenvolvimento. Halpern et al. (1996) em seu estudo sobre o desenvolvimento infantil relata características biológicas da população infantil como fatores determinantes dos atrasos cognitivo e motor da criança. Outros estudos revelam que o desenvolvimento e o uso de habilidades integram diversos sistemas e funções do indivíduo em constante interação com o ambiente físico e social. Sameroff (1997) relaciona o desenvolvimento humano com efeitos advindos da família, do meio ambiente e da sociedade. Segundo Coste(1992), para diagnosticar qualquer disfunção psicomotora ou psicossomática, não se deve levar em consideração apenas os sintomas, órgãos e funções corporais, mas toda a personalidade, situação social, ambiente cultural e condições afetivas dos indivíduos. Diante disso, faz sentido dizer que, neste estudo, o nível socioeconômico familiar e o meio em que estão inseridas podem influenciar no desenvolvimento psicomotor das crianças avaliadas. Conforme é possível observar nos resultados apresentados neste estudo, grande parte das famílias não possui renda mensal total acima de $\mathrm{R} \$$ 800,00, e em média de 4 a 5 indivíduos moram na mesma residência e tem suas despesas pagas a partir desta renda. De acordo com Córdova e Orellana (1996), o baixo nível socioeconômico gera um ambiente adverso para o desenvolvimento psicomotor das crianças, 
pois a pouca variedade de estímulos que este meio oferece nem sempre é compatível com as necessidades que as crianças apresentam para desenvolver suas capacidades intelectuais, motoras, emocionais e sociais.

Outro fator que pode estar relacionado ao baixo desempenho motor dessas habilidades é o ambiente escolar, que também é muito importante para o desenvolvimento da psicomotricidade, pois é nele que a criança permanece grande parte do seu dia.

As escolas têm o papel transcendente de uma "segunda casa” em que muitas crianças provenientes de lares desfeitos com história de alcoolismo, promiscuidade e doença são capazes de encontrar certa segurança. É dentro da escola que os professores devem nutrir um importante fator de proteção na infância que se baseia no cuidado. Dessa forma, os professores que trabalham com crianças em situação de vulnerabilidade social necessitam de um treinamento especial e estratégias concretas para desenvolver o aprendizado a partir da realidade social do seu aluno. (RICHAUD, 2013).

É na escola que as crianças demonstram e desenvolvem uma significativa parte de suas habilidades motoras. Portanto, torna-se importante que os professores utilizem a educação corporal como uma forma de expressão, aprendizagem e comunicação do aluno, objetivando torná-lo um cidadão participativo, capaz de expressar-se, aprendendo a pensar em termos de movimento. Comumente, observa-se na sala de aula uma “educação bancária” onde, na concepção de Freire e Illich (1975), em lugar de comunicar-se, o educador faz “comunicados” e depósitos, e onde os educandos, meras incidências, recebem as informações, sentados, pacientemente, memorizando e repetindo. Eis aí a concepção bancária da educação, em que a única margem de ação que se oferece aos educandos é a de receberem os depósitos, guardá-los e arquivá-los. Nanni (1995) diz que o movimento corporal é de vital importância para o desenvolvimento da criança, pois através de suas habilidades psicomotoras ela expande seus conhecimentos. Conforme Marques (1989), nossas escolas permanecem advogando por um ensino "garantido" (sabemos onde vamos chegar), conhecido (já temos experiências de muitos anos na área), determinado e pré-planejado (não haverá surpresas) e esquecem o quão a educação corporal é importante para modificar esse contexto. Assim sendo, o processo de alfabetização está atrelado ao movimento corporal e não é possível falar do corpo apenas em sua dimensão biológica e instrumental, mas a educação deve atrelar-se principalmente à dimensão cultural. Serafin, Peres e Corseuil (2000) também corroboram os resultados do presente estudo e apontam que a educação escolar tem grande influência no comportamento motor de crianças. Em seu estudo, que avaliou 207 crianças de escolas públicas, a área de maior comprometimento motor foi a de organização espacial, e ele sugere que esse baixo escore possa ser decorrente de uma deficiência na educação brasileira. Os estudos de Crippa e Liamara (2003) também corroboram com essa ideia. Utilizando a EDM, avaliou-se o desenvolvimento psicomotor em crianças de 4 e 5 anos e observou-se atraso no desenvolvimento do esquema corporal em relação à idade cronológica destas crianças. Os autores inferiram que o déficit apresentado pode ocorrer devido a restrições de atividades de simetria corporal, expressão corporal e equilíbrio postural.

A avaliação psicomotora visa identificar fatores que estejam causando algum atraso no processo de ensino-aprendizagem, ou seja, visa contribuir de forma pedagógica e para o desenvolvimento integral da criança, tendo em vista o aspecto mental, psicológico, social, cultural e físico a que ela pertence. As 
escolas ainda têm uma característica muito mecanicista instalada na educação e, por isso, muitas vezes, esquece-se da importância de uma avaliação e um enfoque psicomotor. Os professores preocupados com a leitura e a escrita, por vezes, não sabem como resolver as dificuldades de aprendizagem apresentadas pelos alunos, quando, na realidade, muitas dessas dificuldades poderiam ser resolvidas na própria escola e até evitadas se houvesse um olhar qualificado e atento dos agentes educacionais para o desenvolvimento psicomotor.

As limitações do presente estudo estão relacionadas com o pequeno número da amostra e com a falta da análise das atividades que esses alunos realizavam extraclasse, pois essa análise poderia também ter influenciado os resultados. Cabe também apontar que análises adicionais, com outras escalas ou testes psicomotores mais específicos para crianças em situação de risco, poderiam ser realizadas.

\section{Conclusão}

Diante dos resultados apresentados, conclui-se que déficits em parâmetros psicomotores, como esquema corporal, organização espacial e temporal e lateralidade cruzada ou indefinida, podem estar relacionados à dificuldade de aprendizagem e baixa taxa de alfabetização apresentadas pelas crianças que se encontram em situação de risco social avaliadas neste estudo. Estes resultados chamam a atenção para o acompanhamento do perfil psicomotor de crianças em idade escolar, que constitui uma atitude preventiva e diagnóstica para os profissionais envolvidos com a aprendizagem, tornando possível um conhecimento mais aprofundado das possibilidades e limitações reais da criança. Além disso, esta avaliação pode contribuir para a formulação de estratégias que envolvam a vivência e exploração corporal de forma a estimular o desenvolvimento psicomotor e a facilitar o processo de alfabetização. Ressalta-se, ainda, o importante papel do ambiente (social e escolar) e da exploração corporal no desempenho das crianças, considerados essenciais para o desenvolvimento psicomotor e aprendizagem adequados.

\section{Referências}

ANDRACA, Y. et al. Factores de riesgo para el desarrollo psicomotor en lactantes nacidos en óptimas condiciones biológicas. Revista de Saúde Pública [online], São Paulo, v. 32, n. 2, p. 138-147, 1998.

AYLWARD, G. P. Infant and childhood neuropsychology. New York: Plenum Press, 1997.

BRASIL. Estatuto da Criança e do Adolescente. Câmara dos Deputados. Lei no 8.069, de 13 de julho de 1990. Diário Oficial da União, Brasília, 16 jul. 2003. Disponível em: < http://www2.camara.leg.br/legin/fed/ lei/1990/lei-8069-13-julho-1990-372211publicacaooriginal-1-pl.html>. Acesso em: 15 mar. 2015.

CÓRDOVA, L. S.; ORELLANA, M. J. La educación programada como una estratégia para mejorar el desarrollo psicomotor del pré-escolar. Rev. Horizonte de Enfermeria, Santiago, v. 7, n. 1, p. 52-58, 1996.

\section{COSTA, S.H.Perfilmotordecriançasde 05a} 14 anos com dificuldade na aprendizagem, 2000. Monografia (Graduação em Educação Física). Universidade do Estado de Santa Catarina, Florianópolis, 2000.

COSTE, J. C. A psicomotricidade. Rio de Janeiro: Guanabara: 1992.

CRIPPA, M.; LIAMARA, R. Avaliação motora de pré-escolares que praticam atividades recreativas. Revista de Educação 
Física/UEM, Maringá, v. 14, n. 2. p. 13-20, 2003.

DIBA, K.; BUZSÁKI, G. Forward and reverse hippocampal place-cell sequences during ripples. Nature neuroscience [online], Basingstoke, v. 10, n. 10, p. 12411242, out. 2007.

DEFONTAINE, J. Manuel de reeducation psychomotrice. Tomes 1-4, Paris: Maloine S/A, 1981.

FERREIRA, J. R. P. Saúde escolar: aspectos biopsicossociais de crianças com dificuldades de aprendizagem. Florianópolis, 2007, 114 f. Dissertação (Mestrado em Ciências em Movimento Humano). Centro de Ciências da Saúde e do Esporte -CEFID. Universidade do Estado de Santa Catarina, Florianópolis, 2007.

FONSECA, V. Manual de observação psicomotora: significação psiconeurológica dos fatores psicomotores. Porto Alegre: Artes Médicas, 1998.

FONSECA, F. R.; BELTRAME T. S.; TKAC, C. M. Relação entre o nível de desenvolvimento motor e variáveis do contexto de desenvolvimento de criança. Revista da Educação Física/UEM, Maringá, v. 19, n. 2, p. 183-194, abr./jun. 2008.

FREIRE P.; ILLICH, I. Dialogo: análisis crítico de la “desescolarización” y “concientización” en la coyuntura actual del sistema educativo. Buenos Aires: Busqueda, 1975.

GALLAHUE, D. L.; OZMUN, J. C. Compreendendo o desenvolvimento motor: bebês, crianças, adolescentes e adultos. São Paulo: Phorte, 2001.

HALPERN, R.; BARROS, F. C.; HORTA, B. L.; VICTORA, C. G. Desenvolvimento neuropsicomotor aos 12 meses de idade em uma corte de base populacional no sul do Brasil: diferenciais conforme peso ao nascer e renda familiar. Cad. Saúde Pública, Rio de Janeiro, v. 12, n. 1, p. 73-78, 1996.

LE BOULCH, J. A educação pelo movimento: a psicocinética na idade escolar. Porto Alegre: Artes Médicas, 1992.

La educación psicomotriz em la escuela primaria. Buenos Aires: Paidós, 1987.

LIMA, A. S.; BELTRÃO, I.; LOPES, S. M. Vygotsky e Piaget: um estudo comparativo. Manaus: Edua, 2001.

MARQUES, I. Dance in the curriculum: the Brazilian case, Londres, 1989. Dissertação (Mestrado em Dança - MA in Dance Studies). Laban Centre for Movement and Dance, Londres, 1989.

MEDINA, J.; ROSA, G. K. B.; MARQUES, I. Desenvolvimento da organização temporal de crianças com dificuldades de aprendizagem. Revista Educação Física/ UEM, Maringá, v. 17, n. 1, p. 107-116, 2006.

MEUR, A.; SATAES, L. Psicomotricidade: educação e reeducação. São Paulo: Manole, 1989.

NANNI, D. Dança educação: princípios, métodos e técnicas. Rio de Janeiro: Sprint, 1995.

NEIRA, M. G. Educação Física: desenvolvendo competências. São Paulo: Phorte, 2003.

OLIVEIRA, G. C. Psicomotricidade: educação e reeducação num enfoque psicopedagógico. Rio de Janeiro: Vozes, 2001.

Psicomotricidade: um estudo em escolares com dificuldades em leitura e escrita. Campinas, 1992, 371 f. Tese (Doutorado em Educação). Faculdade 
de Educação. Universidade Estadual de Campinas, Campinas, 1992.

PACHER, L. A. G. Lateralidade e educação física. Instituto Catarinense de PósGraduação. Disponível em: < http://www. icpg.com.br/artigos/rev03-09>. Acesso em: 11 nov. 2015.

RICHAUD, M. C. Contributions to the study and promotion of resilience in socially vulnerable children. American Psychologist, Washington, v. 68, n. 8, p. 751-758, nov. 2013.

RODRIGUES, L. R. Caracterização do desenvolvimento físico, motor e psicossocial de pré-escolares de Florianópolis - SC. Florianópolis, 2000, 198 f. Dissertação (Mestrado em Ciências do Movimento Humano). Centro de Ciências da Saúde e do Esporte - CEFID. Universidade do Estado de Santa Catarina, Florianópolis, 2000 .

ROSA NETO, F. Manual de avaliação motora. Porto Alegre: Artes Médicas, 2002.

ROSA NETO, F.; LEITE, L.; MELO, R. R. F. O perfil motor de alunos atletas de 08 a 10 anos que praticam regularmente natação. ENCONTRO LATINO AMERICANO PARA ESTUDOS DA CRIANÇA: DESENVOLVIMENTO INFANTIL, 2., 2002, Florianópolis. Resumos... Florianópolis: UDESC-CEFID, 2002.

ROSA NETO F.; POETA, L. Intervenção motora em uma criança com transtorno do déficit de atenção/hiperatividade (TDAH). Lecturas: educación física y deportes, Buenos Aires, v. 89, p. 137-150, out. 2005.

ROSANETO,F.;POETA,L.S.;COQUEREL, P. R. S.; SILVA, J. C. Avaliação motora em escolares com problemas na aprendizagem escolar. Temas sobre desenvolvimento, São Paulo, v. 13, n. 74, p. 19-24, maio/jun. 2004.
ROSA NETO, F.; SANTOS, A. P. M.; XAVIER, R. F. C.; AMARO, K. N. A importância da avaliação motora em escolares: análise da confiabilidade da Escala de Desenvolvimento Motor. Revista brasileira de cineantropometria e desempenho humano, Florianópolis, v. 12, n. 6, p. 422-427, 2010.

SAMEROFF, A.; SEIFER, R.; BAROCAS, $\mathrm{R}$. Intelligence quotient scores of 4 years old children: social emotional risk factors. Pediatrics, United States, v. 79, n. 3, p. 343350, mar. 1987.

SERAFIN, G.; PERES, L. S.; CORSEUIL, H. X. Lateralidade: conhecimentos básicos e fatores de dominância em escolares de 7 a 10 anos. Caderno de Educação Física e Esporte, Marechal Cândido Rondon, v. 2, n. 1, p. 11-30, 2000.

VILAR, C. E. C. Dificuldades de aprendizagem e psicomotricidade: estudo comparativo e correlativo das competências de aprendizagem acadêmicas e de fatores psicomotores de alunos do $2^{\circ}$ e $4^{\circ}$ ano do ensino básico, com e sem dificuldades na aprendizagem. Lisboa, 2010, $69 \mathrm{f}$. Dissertação (Mestrado em Reabilitação Psicomotora). Faculdade de Motricidade Humana. Universidade Técnica de Lisboa (UTL), Lisboa, 2010.

VILLAS, B.; BENIGNA, M. F. Planejamento da avaliação escolar. Pró-posições, Campinas, v. 9, n. 3, p. 19-27, nov. 1998. 